Doi: 10.22201/cimsur.18704115e.2021.v16.523

\title{
Percepción de la COVID-19 entre la población indígena zoque de Chiapas
}

\section{Perception of COVID-19 in the Zoque indigenous population of Chiapas}

\author{
Laureano Reyes Gómez 1 \\ (iD) https://orcid.org/0000-0001-5181-060X \\ Instituto de Estudios Indígenas-Universidad Autónoma de Chiapas, México
}

Resumen

Este trabajo explica cómo la pandemia provocada por el coronavirus (COVID-19) tiene presencia en la población nativa zoque de Chiapas. También se muestran las posibles fórmulas terapéuticas que poseen para combatirla o disminuir sus riesgos. El artículo busca entender y exponer un panorama sobre la concepción indígena de la enfermedad, el origen causal y la clasificación térmica de los padecimientos. A través de una metodología cualitativa se contrasta la visión de la medicina zoque y se analiza cómo la población indígena percibe la pandemia por COVID-19. Desde la visión indígena, se cree que el coronavirus se hace presente a través de un «aire sucio», contaminado de «propiedad fría» y potencialmente dañino y, además, se considera como probable causa de muerte. Así, las enfermedades desde la visión zoque tienen su origen en tres fuentes bien definidas: las de origen natural, las de origen sobrenatural y las autoinfligidas.

Palabras clave: indígenas, pandemia, «aire sucio», «aire sano»

Abstract

This paper explains how the pandemic caused by coronavirus (COVID-19) manifested among the Zoque people in Chiapas State. It also introduces possible therapeutic formulas that the Zoque people used in order to fight the virus or reduce its risks. The paper aims to understand and present a panorama of the indigenous understanding of the disease, its causal origin, and the temperature-related classification of the afflictions it produces. Through the use of a qualitative methodology, a contrast with the Zoque medicine perspective is presented and the way the Zoque people perceive the COVID-19 pandemic is analyzed. From an indigenous perspective, coronavirus is explained through the presence of "dirty air," polluted by a "cold quality" that is potentially harmful. Besides, it is considered to be a likely cause of death. According to the vision held by the Zoque people, diseases can have their causal origin in three clearly defined sources: those of natural origin, those of supernatural origin, and those that are self-inflicted.

Key words: indigenous, pandemic, «dirty air», «healthy air» 


\section{Introducción}

a pandemia COVID-19 que azota al mundo entero ha llegado a México. Los medios de comunicación masiva alertaron sobre la amenaza que representa el coronavirus para la salud, y el 27 de febrero de 2020 se confirmó el primer caso positivo en nuestro país, evento que marcó el ingreso a la fase 1 de la pandemia por contagio exportado; el 19 de marzo se registró la primera causa de muerte por coronavirus y el 23 de marzo inició la campaña de «Sana distancia». El 25 de marzo se declaró el ingreso a la fase 2, con 993 casos positivos y 20 muertes (Infobae, 2020b) y el 21 de abril a la fase 3 de la pandemia con 12872 casos confirmados y 1221 defunciones (Infobae, 2020e).

De acuerdo con el sistema de monitoreo del semáforo COVID que indica el nivel de afección por zonas geográficas, el 18 de mayo se fijó como fecha de regreso paulatino a actividades y se estableció un retorno progresivo a la «nueva normalidad». El semáforo epidémico cuenta con cuatro indicadores: rojo, «máxima alerta sanitaria», que permite la operación de actividades esenciales (minería, construcción de equipos de transporte); naranja, "alto», que marca el inicio de actividades esenciales y algunas no esenciales exigiendo un máximo cuidado a trabajadores vulnerables; amarillo, «intermedio», que permite actividades acotadas en el espacio público y la actividad económica plena; el verde, «cotidiano», finalmente indica la reanudación de actividades escolares, sociales y de esparcimiento así como una actividad económica en totalidad (Infobae, 2020d). En ese momento, las zonas identificadas con semáforo en verde fueron aquellos municipios que no habían registrado infección de COVID-19 y sus municipios vecinos se encontraban libres de contagio, es decir, se trataba de poblaciones serranas y por lo tanto alejadas de grandes núcleos de población. En México se registraron 269 municipios en semáforo verde en 15 estados (Infobae, 2020e).

El 1 de marzo de 2020, en Tuxtla Gutiérrez (la capital del estado de Chiapas), aun estando en la fase 1 de la pandemia se registró el primer caso confirmado de coronavirus (El informador, 2020). La noticia causó cierto temor entre la población, aunque otras personas consideraron que se trataba de un caso aislado de infección importada. El 27 de abril de 2020 Chiapas ya registraba 136 casos confirmados y siete defunciones (Milenio, 2020a), ubicando al estado en $5^{\circ}$ lugar (de 31 estados y la Ciudad de México) de menor contagio en la república mexicana.

Las autoridades sanitarias federales lanzaron, con profunda insistencia, varias acciones a seguir, esto con el objetivo de disminuir los riesgos de la pandemia y «aplanar» la curva de incidencia. Así: 
A partir del 23 de marzo se suspendieron las clases por un mes, [incluidas] las actividades no esenciales, se cancelaron eventos masivos, se pidió a la población evitar aglomeraciones, aislarse en sus casas y mantener un alejamiento físico para disminuir el riesgo de contagio y proteger a los adultos mayores (Infobae, 2020b).

De igual manera —especialmente durante la fase 2- se instrumentaron programas como «Sana distancia», "Quédate en casa» y "Lávate las manos»; se prohibió el saludo de beso y abrazo y en varios estados de la república, como Chiapas, se declaró ley seca.

En Chiapas el 39.5 \% de los 124 municipios han presentado casos positivos de COVID-19, es decir que en el 60.5 por ciento podrían regresar paulatinamente a sus actividades el próximo lunes 18 de mayo con la suspensión de la Jornada Nacional de Sana Distancia y la puesta en marcha de la Nueva Normalidad (Náfate, 2020).

El 16 de mayo se dio a conocer en Chiapas el listado de «municipios de la esperanza», es decir, aquellos que se mantenían en semáforo verde. Los cinco municipios se encontraban en la zona norte del estado, cuatro de ellos en territorio zoque: Pantepec, Tapilula, Rayón y Tapalapa (pueblos zoques) y Rincón Chamula (pueblo tsotsil). Sin embargo, era evidente que el riesgo de sufrir contagio era latente (Infobae, 2020a).

La política sanitaria recomendada era quedarse en casa y cumplir las reglas de higiene. Se puso énfasis en el apoyo a las personas mayores por considerarse un sector vulnerable, con incidencia de comorbilidades como diabetes, hipertensión arterial, sobrepeso, obesidad, asma, entre otras, así como por llevar, en general, una vida más sedentaria. De igual forma, el 1 de junio se estableció —una vez más - una fecha de regreso a la «nueva normalidad» (1 de junio), al tiempo que se esperaban brotes pandémicos. Las respuestas a estas acciones, en especial por parte de la población nativa zoque, son el origen de este artículo, el cual busca explicar, desde la cultura nativa, las percepciones y acciones ante la multicitada pandemia.

\section{Metodología}

El trabajo, aunque se refiere a la población zoque en general, se basa principalmente en datos provenientes del sector católico de Copainalá y Tapalapa, Chiapas; ahí se entrevistó vía telefónica a cinco personas que mantenían la cua- 
rentena en casa. En otros casos, la información es producto de la comunicación continua con programas de radio sobre COVID en la región de estudio a través de la radio bilingüe (zoque-castellano, tsotsil-castellano) XECOPA La Voz de los Vientos, de Copainalá. También se hizo un seguimiento puntual, a través de llamadas telefónicas, a dos pacientes jóvenes tratados con medicina «popular» y en fase de recuperación de una «tosecita» identificada con cuadro clínico de disnea (dificultad respiratoria), hipertermia, anosmia (pérdida de olfato), ageusia (pérdida del gusto), cefalea, diarrea, adinamia (pérdida de fuerza) entre otros signos y síntomas patológicos asociados con COVID; en el ámbito social la enfermedad no fue declarada como tal por temor a sufrir agresiones discriminatorias y segregacionistas por parte de vecinos, así que el manejo fue en secreto. Además, la información etnográfica se alimenta de trabajos previos a la pandemia realizados en la zona zoque en materia de antropología médica, así como de reportes hemerográficos y bibliografía especializada sobre etnomedicina. Cabe insistir en que el trabajo etnográfico durante la pandemia se hizo a distancia, vía telefónica.

Es importante referir que se participó activamente con 13 cápsulas de radio bilingüe La Voz de los Vientos, destinadas a sensibilizar a la población indígena con respecto a la pandemia COVID-19. Asimismo, se buscó incidir en la disminución de los riesgos de contagio a través del programa Reporte 12:10, diseñado para tratar asuntos relacionados con la pandemia en cuestión.

\section{Los zoques de Chiapas}

La familia lingüística mixe-zoque se integra con mixes y zoques de Oaxaca, zoques de Tabasco y popolucas del sur de Veracruz. Los zoques de Chiapas se hacen llamar a sí mismos O'de pët 'gente de idioma', literalmente 'palabra de hombre', sinónimo de verdad o verdadero, es decir 'los auténticos' (Reyes, 1988: 171). En la variante culta de la lengua, Villasana (1995) registró a los zoques de Copainalá, Chiapas como suñipë. Esta designación tiene dos componentes lingüísticos: suñi = 'bonito', 'bello', 'hermoso' y pë = es el marcador de persona; es decir, se identifican como los bellos, los bonitos, los agradables, los hermosos, los lindos e incluso como los sabrosos (Villasana, 1995: 209). La región zoque se ubica al noroeste del estado de Chiapas, en el sureste mexicano y lo integran tres zonas geográficas: la Depresión Central, la Zona Serrana y la Depresión al Golfo de México (Villasana, 2006: 76). Según información del Instituto Nacional de Estadística y Geografía ( INEGI), la población zoque de Chiapas es de 65355 hablantes nativos ( INEGI, 2010). La lengua zoque de Chiapas no pertenece a la familia lingüística maya, sino que está afiliada a las lenguas mixe-zoqueanas.

\section{4}

Revista Pueblos y fronteras digital • volumen 16 • 2021, pp. 1-23•ISSN 1870-4115 


\section{Política sanitaria oficial}

El 23 de marzo de 2020 se declaró la Jornada Nacional de Sana Distancia, con el objetivo de «iniciar a tomar acciones previas a la transición a la fase 2 de contagio para reducir la tendencia de casos de COVID-19» (Infobae, 2020c). Para el propósito anterior, considerando los criterios de la Organización Mundial de la Salud (OMS, 2020), se proyectó la suspensión de clases por un mes; de igual forma, se sugirió evitar reuniones de más de 25 personas, así como la suspensión inmediata de actividades no esenciales en los sectores público, privado y social, esto del 30 de marzo al 30 de abril. Para atender la emergencia sanitaria, cinco grupos fueron considerados esenciales: 1) rama médica y paramédica, administrativa y de apoyo para el sector salud tanto en el campo público como privado; 2) las involucradas en la seguridad pública, la protección ciudadana, la defensa de la integridad y la soberanía nacional, la procuración e impartición de justicia, la actividad legislativa estatal y federal; 3) los sectores esenciales para el funcionamiento fundamental de la economía; 4) la operación de los programas sociales del gobierno y 5) conservación y mantenimiento de la infraestructura crítica que asegura la producción y distribución de servicios indispensables (agua, energía, drenaje, saneamiento básico, etcétera) (Diario Oficial de la Federación, 2020).

Asimismo, se instrumentaron programas como «Quédate en casa» y «Susana distancia». Se recomendó el lavado frecuente de manos, estornudar o toser con etiqueta respiratoria, saludar a distancia y no de beso ni de mano o abrazo. Posteriormente se recomendó el uso de cubrebocas y mascarilla, gel antibacterial y tapetes sanitizantes. Para hacer llegar la información de los programas a las comunidades indígenas se tradujo a diferentes idiomas originarios y fue difundida a través de la radio, TV, internet y medios impresos. Sin embargo, en varios grupos étnicos, la transmisión escrita u oral sobre la pandemia no fue exitosa:

En la zona, los gobiernos federal y estatal han difundido mensajes escritos que, aunque estén redactados en lenguas indígenas, la mayoría no sabe leer, además de que son sociedades de tradición oral. También hay difusión de mensajes a través de una radiodifusora, pero resultan muy técnicos para la población y no generan conciencia alguna sobre lo que está por venir. No vemos acciones orientadas a establecer una comunicación acorde con la idiosincrasia de los pueblos, sus idiomas, su cultura; que mínimamente se garantice una información accesible, no tan técnica (Camacho, 2020). 
Por otro lado, la preocupación de los pueblos indígenas ante el desarrollo de la pandemia era latente dada la desprotección en materia de atención en servicios de salud. Esta es una aflicción que varias familias comparten, en especial las que viven en ciudades y sus similares en las aldeas nativas:

Para evitar el contagio, la OMS [Organización Mundial de la Salud] y los gobiernos recomiendan lavarse las manos, y nosotros no tenemos agua potable para el consumo; sana distancia, y nosotros vivimos hacinados y en campamentos; resguardarse en casa

y nosotros no tenemos casa: vivimos en la calle, fuimos desalojados; hacer cuarentena, y somos desempleados, trabajamos en la calle y vivimos al día (Camacho, 2020).

A pesar de que existe, en el mejor de los casos, el uso correcto del cubrebocas y la aplicación de gel antibacterial y mascarilla, la «sana distancia» pocas veces es observada. La gente tiene que trabajar en sus parcelas y la política de quedarse en casa es nula; en algunos casos solamente en el centro de las respectivas localidades sí era vigilado el cumplimiento de ciertas restricciones sanitarias, en particular en espacios públicos como el mercado, el parque y tiendas. En el transporte público se recomendó disminuir el número de pasajeros y ejercer el uso obligatorio de cubrebocas, acción revisada en retenes al ingreso y salida de las localidades; de igual forma se prohibió la asistencia a fiestas masivas, aunque celebraciones religiosas como las fiestas patronales siguieron su curso normal o con menor afluencia. Los rumores de que algún vecino estaba contagiado de coronavirus avivaron la estigmatización y discriminación hacia los pacientes. Las personas sospechosas de haber contraído el virus declaraban tener otro padecimiento socialmente aceptable y renombraban su enfermedad como «tosecita», «melancolía», «dolor muscular» y muy comúnmente, resfriado común acompañado de dolor de garganta.

\section{Etiología de los padecimientos desde la medicina indígena}

Para poder entender la perspectiva de la medicina indígena frente a la pandemia es preciso conocer la etiología de las enfermedades desde la visión de la etnomedicina. Así, podemos identificar tres tipos de padecimientos según su origen causal: los de clasificación natural, los considerados de etiología sobrenatural y los tipificados como autoinfligidos. A su vez, cada padecimiento puede ser clasificado de propiedad fría (letalidad alta), caliente (letalidad media) o templada 
(letalidad baja), salvo contraindicación del especialista; el diagnóstico será emitido por el terapeuta considerando varios factores, como tipo de alimentación, condición climática o tarea realizada (véase Figura 1).

Figura 1. Etiología, propiedad térmica y letalidad de los padecimientos en la etnomedicina zoque

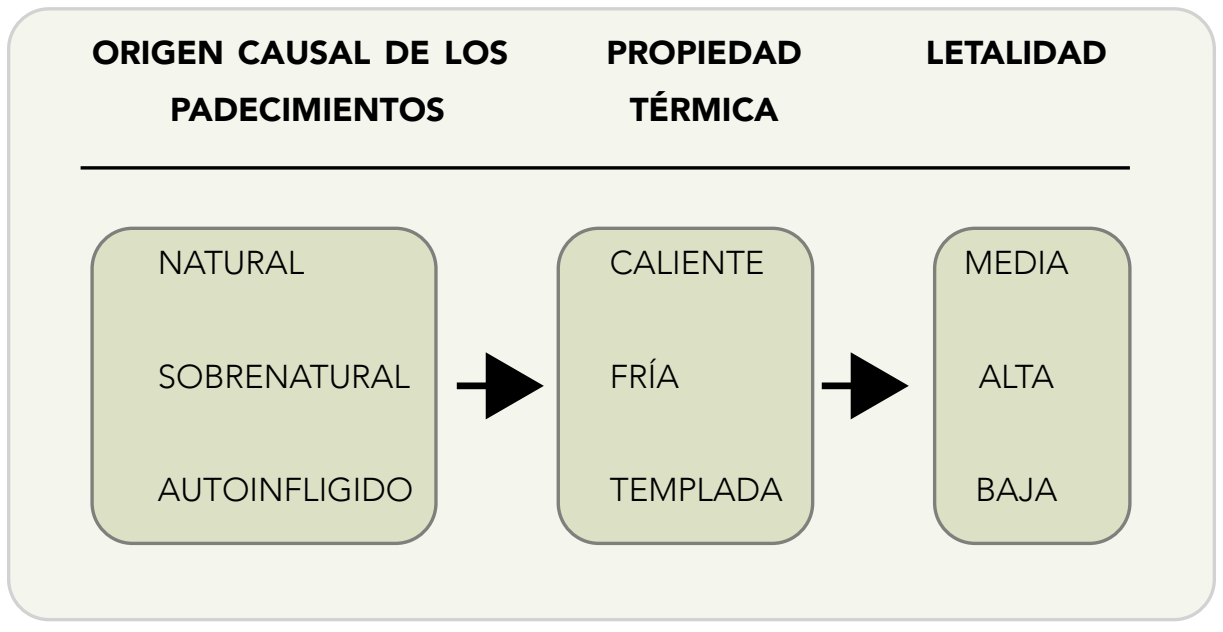

Fuente: Elaboración propia con datos de campo, abril de 2020.

Los padecimientos de origen natural son todos aquellos adquiridos desde el exterior, no por contagio directo, sino como resultado de la sobreexigencia o el abuso de algunos comportamientos que afectan el organismo humano, al violentar o desequilibrar el balance, principalmente en las nociones de frío/caliente, seco/húmedo, pesado/ligero y antojo/abuso. Esta última noción está referida al monto de la ingesta, es decir, llevar el consumo más allá del antojo, lo cual provoca daños en la salud. Todo debe guardar un equilibrio.

Al respecto, existen distintos padecimientos de origen natural, entre ellos: la calentura, que surge por violentar el organismo al pasar repentinamente de ambientes fríos a calientes; el empacho, que se sufre, por ejemplo, por la intolerancia o el abuso en la ingesta de algunos alimentos o bebidas; las diarreas, explicadas por el desbalance térmico que sufre el estómago al sobrecargar alimentos de propiedades contrarias como frío/caliente o pesado/ligero; los dolores musculares, asociados con la sobreexigencia en la actividad física o el resultado de golpes o desgarres. Existen muchos ejemplos, pero basta con estos para tener una idea de cómo se explican estos padecimientos clasificados de origen natural. Los remedios generalmente son caseros y se aconseja vigilar el balance entre 
las propiedades ya referidas anteriormente. Su letalidad como causa de muerte es baja. La propiedad fría, caliente o templada de los padecimientos (en particular los relacionados con la alimentación) está asociada con la identificación y clasificación térmica preestablecida por los terapeutas y generalmente son de conocimiento popular.

Los padecimientos de origen sobrenatural, en cambio, son más complejos en cuanto a la forma de contraer la enfermedad. En este terreno, las enfermedades se clasifican de acuerdo con su propiedad fría o caliente. La víctima es atacada por agentes malévolos a través del alter ego, es decir, la tona o tonalli, el animal compañero o el «espíritu» que le corresponda. La tona implica que el animal compañero y la persona corran suertes paralelas; así, lo que le pasa a la persona lo experimenta el animal compañero, y viceversa. Otros grupos étnicos de origen nahua y maya comparten esta nosología. Véanse, por ejemplo, los trabajos de López-Austin (1980), Pitarch (2000) y Page (2011), entre otros.

Las enfermedades sobrenaturales de origen frío son más difíciles de tratar y están asociadas a la alta letalidad, toda vez que el «espíritu» del paciente es retenido por agentes sobrenaturales que manipulan — desde el inframundo o por conducto de hechiceros - la salud de la víctima. Se requiere, entonces, el concurso de especialistas capaces de luchar contra fuerzas sobrenaturales buscando reintegrar el «espíritu» a la persona. Es común que en el diagnóstico del paciente se infiera que el padecimiento fue adquirido a través de un sueño donde su alter ego fue atacado o hecho prisionero por hechiceros en algún lugar remoto y es preciso recuperarlo por medio de ritos muy elaborados que implican, principalmente, rezos y ofrendas de aves como víctimas alternas. Así, también, en represalia hay enfermedades enviadas por muertos, por ejemplo, por no haber cumplido cabalmente ceremonias que dicta la costumbre en diversos actos como los mortuorios. Los tratamientos son prolongados y requieren cuidados especiales y atención por parte de la terapéutica indígena. Los pacientes que sufren enfermedades sobrenaturales de propiedad fría, generalmente padecen dolores agudos, melancolía crónica y pierden interés por la vida. De no atenderse por medio de la terapéutica indígena, podrían morir.

Al considerar la clasificación etiológica anterior podemos identificar — desde la concepción zoque de Copainalá- la idea de que el coronavirus recorre grandes distancias a través del aire sucio contaminado y es una amenaza externa; su diseminación no se atribuye al hombre como agente transmisor directo, sino como efecto del aire contaminado por el virus, que amenaza al hombre. 
Correspondería a la categoría de padecimiento sobrenatural, de naturaleza fría y letalidad alta. La idea de que el virus se transporta vía aérea, por un lado, está influenciada por la información oficial de los servicios de salud; por otro lado, en la concepción indígena zoque existen aires sanos que protegen, y aires sucios que transportan enfermedades, malos olores y calamidades que causan daño a la salud; ambos aires entablan luchas por conquistar territorios.

El coronavirus se identifica entonces como un virus potencialmente agresivo y causa probable de muerte. Su contagio se produce al respirar/aspirar por la nariz o boca el aire frío contaminado. La manifestación clínica se identifica por la tos, calentura, dificultad respiratoria, dolores intensos en articulaciones, pérdida del sentido del gusto y olfato, inapetencia, desorientación, diarrea, entre otros síntomas. Provoca un dolor agudo. El paciente experimenta sufrimiento y ansiedad profundos y la probabilidad de muerte es alta. En idioma zoque empieza a circular el nombre del coronavirus bajo la designación de toyaka'kuy (toya 'dolor y sufrimiento profundos'; ka'kuy 'enfermedad con probabilidad de muerte'); es decir «enfermedad que produce dolor profundo, asociada con la probabilidad de morir». Con la castellanización del virus también se le identifica popularmente como kobidka'kuy, es decir: enfermedad de COVID que puede derivar en muerte.

En cambio, las enfermedades sobrenaturales de origen caliente son de menor amenaza para la salud; no obstante, causan molestias persistentes que requieren ser atendidas con urgencia. Estos padecimientos sobrenaturales de propiedad caliente provienen de los conflictos de la convivencia social humana, de los accidentes en la vida terrena y no se originan desde el inframundo. Otro de los padecimientos de origen caliente son las envidias, es decir, esa sensación imperiosa e irracional de poseer lo que el otro tiene en buena lid; en estos casos quien enferma es el envidiado y no tanto el envidioso. Se cree que el aire o la mirada caliente ingresa a través de los ojos y está reservado para padecimientos de propiedad «caliente», como las envidias y el mal de ojo u ojeadura. Las envidias se manifiestan acompañadas de hipertermia y cuadros diarreicos. El estudio de la envidia entre los choles ha sido tratado ampliamente por Imberton (2002).

Asimismo, el susto es otro padecimiento común que necesita tratamiento, toda vez que es causa de muerte si no es atendido según los cánones que dicta la terapéutica indígena. Las caídas en los ríos y otros cuerpos de agua, así como la sensación de ahogo en la persona, son padecimientos que «secan» el cuerpo; es decir, el paciente experimenta falta de apetito, pérdida acelerada de peso, deshidratación y duerme con sobresaltos. Este padecimiento está ampliamente 
registrado en varios lugares no solo de México, sino de otras latitudes; al respecto véase por ejemplo el trabajo de Zolla, Campillo y Bosque (1988).

Finalmente, están los padecimientos clasificados como autoinfligidos, en forma consciente o inconsciente. Por ejemplo, al hablar de las adicciones, la persona hace uso de sustancias ilegales y se provoca — por decisión - un daño en la salud. Otro tanto sucede con el tabaquismo y especialmente con la flojera crónica, aquella agarrotada que «nace de los huesos» y orilla a la persona a sobrevivir de la mendicidad y la vagancia. Son padecimientos, generalmente, de propiedad fría que complican la situación de salud de la persona y los vuelve presa fácil de la muerte a edades tempranas. Se tiene la convicción de que estas enfermedades son autocultivadas, por lo que está en manos del paciente superar la condición.

La flojera aguda —en particular la que orilla al cuerpo a la pereza, esa que desborda en toda la anatomía, como dicen los zoques: «la dejadez» en grado crónico- se manifiesta en negligencia intencional, autoabandono, desgano, desinterés, apatía, desidia, indolencia, vagancia y muchas reacciones de incuria que causa verdaderos estragos en todas las esferas de la vida en quienes la padecen o cultivan. Por fortuna, la flojera crónica «que nace de los huesos» no es considerada un padecimiento transmisible, sino que se asume como autoinfligida, es provocada y alimentada por la persona como acto intencional. Es normal que todas las personas en algún momento manifiesten flojera «superficial», pero es una emoción temporal que es superada por la acción. El trabajo, la producción, el ánimo, la motivación, interés y la presión son actitudes que inducen a la superación de la pereza; lo contrario conduce a caer en pecado clasificado como capital. La flojera extrema que experimenta el individuo convierte a la persona en un ser indeseable, antisocial, vago, parásito que vive a expensas de los demás.

\section{Los aires sanos, los aires sucios y el coronavirus}

Los zoques de Copainalá, Chiapas, distinguen entre aire «sano» (templado, fresco) y aire «sucio» (frío). Se dice que el aire sano «ventea bonito» y purifica el ambiente; el aire sucio, en cambio, lleva impurezas como el virus y muchas otras enfermedades, así como olores no deseables. En la opinión de don Damián, de 65 años, el pueblo zoque de Copainalá fue fundado justamente en un sitio donde el «aire sano ventea bonito»; es decir, el aire fresco corre purificando el ambiente. Esa sería la explicación de por qué el coronavirus difícilmente podría alojarse en Copainalá, puesto que sería barrido por el «aire sano». Si algún vecino resulta 
infectado por coronavirus, se asumirá que se contagió fuera de la localidad; un caso como este sucedió el 6 de mayo de 2020, donde una paciente que era migrante de retorno resultó infectada por el virus. La solución para evitar enfermar de coronavirus sería, entonces, habitar espacios donde el «aire sano» limpie de impurezas el ambiente corrupto y procurar que personas especialmente externas a la comunidad no la visiten estando contaminadas del virus. La información estadística reportó que «Chiapas registra la tasa más baja de casos de coronavirus en el país» (López, 2020). Sin embargo, para el 26 de mayo de 2020 Chiapas se ubicaba en el número 16 (de 31 estados y la Ciudad de México, capital) en cuanto a contagio se refiere (Milenio, 2020b). A la fecha, la curva pandémica no se lograba «aplanar». En general, la gente no se acostumbra al uso de cubrebocas y cuando lo hace, generalmente lo porta incorrectamente. El gel antibacterial es escaso y la costumbre de lavarse las manos con jabón es prácticamente nula. Sobre el particular, Ledesma (2020) opina:

Hoy como hace cinco siglos, las pandemias siguen siendo un instrumento de colonización. La población más vulnerable por la llegada de enfermedades han sido los pueblos indígenas generalmente desprovistos de acceso a servicios públicos, infraestructura hospitalaria, aislados por las condiciones geográficas accidentadas y una histórica relación tensa con el Estado (colonial y nacional), que en su conjunto dan una idea del escenario en que enfrentaron las epidemias que surgieron a partir de la colonización española en el siglo XVI.

En la cosmovisión zoque existe el yach sawa (yach, raíz de ya'tsi 'malo'; sawa 'viento'. Una de las palabras para referirse al diablo es justamente Yatsibë, compuesta de ya'tsi: 'malo' y bë, marcador de persona.

Lo opuesto al aire malo es el wëbë sawa (wëbë 'lo bueno'; sawa 'viento'), el aire benigno, el aire bondadoso, el aire sano que ventea. Copainalá, como ya se mencionó, al haber sido fundado en un sitio en el que «aire sano ventea bonito», goza de salud y crea las condiciones propicias para que el coronavirus sea enviado a otras latitudes, lejos, allá donde reina el viento sucio, en grandes núcleos de población y distante de Copainalá.

La idea de que el humano no es agente transmisor directo de enfermedad, sino que los padecimientos son concebidos como amenazas externas (sean de origen natural o sobrenatural), lo salva de ser acusado de provocar daño intencional a menos que se trate de un padecimiento de filiación cultural conocido como «ojo» u «ojeadura», provocado accidentalmente por una suerte de belleza 
que despierta la admiración de quien observa sobre la persona, animal, planta o tarea realizada, y que de esta forma se inyecta — por medio de los ojos- calor en demasía sobre la víctima hasta alterar su estado de salud o condición. Otras veces, la mirada de «ojo caliente» es intencional; cuando esto sucede, la afección ingresa a la perspectiva de envidia y generalmente se sospecha del agresor. Estos padecimientos se atribuyen por acción «de ojo caliente», son de tratamiento doméstico y normalmente no son letales.

Por lo referido, se asume que la COVID-19 es una enfermedad cuyo agente causal es conocido como coronavirus y, dado que no es visible y se transporta por vía aérea, se concibe entonces como "aire frío sucio contaminado» que puede desplazarse, recorrer grandes distancias y estar en los lugares más inhóspitos, dar vuelta en los confines del mundo y regresar en busca de víctimas para alojarse en ellas como huésped no deseado. El humano, al respirar/aspirar aire frío sucio contaminado, se contagia del virus; la persona, una vez infectada, esparce el virus por el aire que exhala. Por consiguiente, se cree que la enfermedad es adquirida por vía aérea a través de nariz o boca. Mucha gente piensa que el contagio del coronavirus no se contrae por vía ocular pues por los ojos se inyecta calor a través de la mirada, pero no frío, como es identificado el virus en cuestión.

Los aires, en realidad, se conciben como agentes vivos y cada uno defiende ferozmente su territorio. El aire sucio contaminado es un enemigo muy poderoso a vencer, su herramienta de conquista — además del miedo que infunde- es dejar sus inmundicias infectando a las personas y matando a los más débiles. Por otro lado, en el pensamiento indígena se cree que hay individuos con poderes suprahumanos que les permiten concentrar en su cuerpo calor en demasía, haciéndolos hasta cierto punto resistentes y capaces de soportar diferentes embates de las enfermedades; esto siempre y cuando cumplan determinadas características físicas que les dan cierta inmunidad, protección o resistencia frente a la amenaza externa (Guiteras, 1988). Las características físicas las tienen los enanos, los gemelos, los albinos y las personas que tienen más de cinco dedos en manos, pies o en ambas extremidades. Son especialmente poderosas aquellas que tienen nueve o más remolinos en el cabello, toda vez que simulan la piel del jaguar pues son personas con arrojo, resistentes ante el embate de amenazas a su salud y otras penurias. La rebeldía de su cabello refleja el poder de no doblegarse a la primera amenaza, estos individuos son de carácter rudo, terco, necio, incisivo y persistente, en términos populares son conocidos como «correosos». Estas personas expresan, entre otras características, algunas indiscreciones que los dela- 
tan: son en extremo longevas, sus enfermedades son pasajeras, gozan de «salud de roble» y a menudo presumen su galanura.

Sin embargo, pocas personas son las afortunadas de contar con esta protección de concentrar calor en su cuerpo, lo cual les brinda las características físicas de inmunidad antes señaladas. Aunque el «viento sucio» los ataque, sobrellevan la enfermedad sin mayores sobresaltos haciendo gala de su defensa o resistencia. La mayoría de la población no cuenta con esta protección natural, por lo que es preciso apoyar a los «vientos sanos» procurando la higiene y otras recomendaciones de las autoridades sanitarias para que el «viento sano» triunfe y eche, de una vez por todas, al viento sucio allá lejos, en los confines de la tierra, en los dominios de las fuerzas malignas, donde le corresponde.

\section{Acciones contra el coronavirus}

En 2020 la pandemia coincidió con la celebración de la Semana Santa y otros actos rituales, periodo que es aprovechado para visitar familiares y disfrutar la fiesta anual que varios pueblos celebran con gran devoción. Varias localidades, específicamente en el sureste mexicano, después de haber tomado acuerdos en asamblea comunitaria y discutir la amenaza a la salud que representa la pandemia, decidieron controlar tanto el ingreso como la salida de los pueblos a través de filtros sanitarios o retenes y bajo varias modalidades.

Así, por ejemplo, hay lugares que han tomado medidas radicales con la sentencia: «si sales ya no entras; si entras, ya no sales». Otros más han emitido acuerdos en los que informan a los paisanos que viven fuera de la localidad, especialmente en ciudades dentro del país y más aún si provienen del extranjero, que no serán admitidos por ser potencialmente sospechosos de ser portadores del coronavirus; por tanto, habrán de abstenerse de viajar a la comunidad, solo tendrán acceso al pueblo a través de los locales donde habitualmente viven y bajo horarios restringidos acordados en asamblea. Por ejemplo, en una pequeña aldea de Oaxaca, cerca del istmo de Tehuantepec, en reunión los vecinos acordaron expulsar a toda aquella persona no nativa del pueblo que hubiera arribado en los últimos tres meses - fecha de inicio de la pandemia - la cual debería abandonar el sitio en un lapso de 24 horas, pudiendo regresar a la comunidad una vez superada oficialmente la contingencia sanitaria. Bajo esta última mirada es posible notar que la amenaza se percibe de fuera y no local. En todos los casos solo era permitido el ingreso de servicios tales como medicinas, alimentos, gas, servicio de emergencias, entre otros. 
Los filtros eran instalados por medio de comisiones y se bloqueaba el ingreso al pueblo con plumas, cadenas u otros artefactos movibles. En una pequeña localidad del sureste mexicano se anunció a través de aparatos de sonido que especialmente el Jueves y el Viernes Santo — por ser días particularmente «calientes»- se prohibía estrictamente salir de las casas y se solicitó mantenerse bajo resguardo. Lo anterior se debió a que el sol emitiría radiaciones de tal naturaleza que se encargarían de matar cuanto virus se encontrara en la calle, en particular aquellos depositados en el suelo. El coronavirus, a decir de los locales, no resiste estar expuesto a temperaturas de más de 40 grados centígrados por tiempos prolongados; el Jueves y el Viernes Santo los termómetros registraron 42 grados centígrados a la sombra. Las únicas personas autorizadas para salir eran los campaneros que tocarían por turnos el repique de «rogativa», solicitando a Dios alejar a los «vientos sucios» y transportar la enfermedad muy lejos del pueblo. La comunidad, por su parte, estando enclaustrada rezaría para que la pandemia no afectara al poblado, quemarían copal y pondrían los machetes en forma de cruz para que «cortara el aire malo» infectado de coronavirus.

Otro acuerdo importante tomado en asambleas consistió en que nadie, absolutamente nadie, estaría autorizado para visitar otras localidades. Esto en especial si se planeaba asistir a fiestas patronales, puesto que en esas festividades concurre gente de otros lugares y podrían contagiarse, lo cual derivaría en contaminar a la población a su regreso.

\section{El desinterés ante la pandemia CoVID-19}

Las causas que motivan la apatía respecto al problema grave de salud que sufre la comunidad ante la amenaza del coronavirus son varias, veamos algunos casos:

La persona desestima, considerando poco importante, la información médica oficial que explica el problema de salud pública ante la amenaza del virus e indica cómo afrontarla para disminuir el riesgo. La apatía como respuesta a la pandemia, entonces, induce a no modificar las costumbres que habitualmente se siguen, exponiéndose a un serio riesgo de ser contagiado y, a su vez, de volverse fuente transmisora del virus en cuestión.

Otro fenómeno que alimenta el desinterés para un cambio de actitud frente a la pandemia es creer más en el rumor transmitido en el vecindario o a través de redes sociales que en la información sanitaria oficial. Así, por ejemplo, hay gente que niega abiertamente la existencia de la enfermedad, con el argumento de 
que todo se trata de un invento para infundir temor en el pueblo y subir el precio de los productos. Este recurso es muy socorrido y mucha gente lo difunde por diversos medios. El no hacer caso a las indicaciones en torno a la contingencia sanitaria resulta, en apariencia, muy cómodo; mucha gente se molesta sobremanera cuando se le reclama su actitud de desacato y hace uso de una trillada frase argumentado que: «de algo nos vamos a morir». El reto de tener a la muerte "cara a cara» o colapsar los servicios de salud carece de importancia y, aparentemente, prevalece el egoísmo y la confianza en la protección de alguna divinidad. Así, varios pueblos no han suspendido concentraciones masivas en festividades patronales con la esperanza de que ninguno de los asistentes sea portador del virus; riesgo que, de ser contagiados, desencadenaría un pandemónium, es decir, un caos absoluto sobre el cual, seguramente, ya no se tendría control.

Otras personas opinan que, en realidad, los efectos en el quebranto de la salud a causa del coronavirus no son letales y no implican mayor riesgo, ya que consideran puede ser tratado rápidamente con una serie de terapias caseras muy similares a cualquier cuadro gripal común. El consumo de limón, la ingesta de alcohol (aguardiente de caña), hacer gárgaras de agua de sal y comer ajo son algunos tratamientos populares que abundan en las redes sociales o que la gente suele usar ante resfriados comunes. Argumentan, además, que la agresividad de la COVID-19 está muy por debajo de otros padecimientos de los cuales hay que preocuparse y requieren mayor atención, tales como como la diabetes, la obesidad, la hipertensión y el tabaquismo, entre otros problemas de salud no contagiosos.

Cuando hay sospecha o confirmación de contagio de COVID-19, la terapéutica recomendada es, además de aislamiento, la ingesta de alimentos de propiedad «caliente» (abundante picante, carne de res, «trago» —aguardiente de caña-, gallina de rancho, camote, infusiones de canela, limón y otros cítricos). Con ello se busca introducir «calor», principalmente en las paredes pulmonares para darle flexibilidad a los tubos respiratorios y permitir una mejor oxigenación. Se privilegia el uso de ungüentos como Vick Vaporub y la administración de ibuprofeno de una a dos pastillas cada ocho horas. Respecto al uso de plantas medicinales, se recurre a vaporizaciones de ruda, manzanilla y canela, considerados particularmente de propiedad térmica «caliente». El mayor temor ante esta enfermedad es morir de asfixia. Evidentemente, el pronóstico de sanar o controlar el padecimiento es mayor en la población joven, fuerte y sana que en personas adultas 
mayores, en particular si padecen comorbilidades y si se trata de cuerpos cansados, débiles y envejecidos.

En este sentido, también circuló la idea de que el virus «le da» a la población no indígena; creyendo que los indígenas, en cambio, tienen un sistema de protección natural, que son más resistentes y han sobrevivido a grandes epidemias en el pasado, por lo que se concluye que han creado resistencias. La población indígena está hecha de «buena madera», a diferencia de los no indígenas «que son débiles». Además, surge la noción de que un gran enemigo del virus es el alcohol ingerido. Si el virus se instala en la garganta hay que «barrerlo» con alcohol; en la población adulta, la dosis recomendada es un par de copas al día que serán suficientes para eliminarlo o disminuir su amenaza.

El autocuidado ante la amenaza del coronavirus se aprecia muy lejano. Mucha gente tiene que trabajar fuera de casa, pero las costumbres de higiene como lavarse las manos frecuentemente con agua y jabón, cubrirse la boca con un pañuelo o con el ángulo interno del brazo al estornudar o toser, practicar el distanciamiento social no saludando de mano ni de abrazo y guardar una sana distancia y no escupir, parecen ser costumbres difíciles de incorporar.

\section{El rechazo social a los infectados de coronavirus}

El comportamiento humano ante una pandemia es realmente complejo. Involucra no solo al paciente mismo, sino a la familia, al personal de salud y a los vecinos en general. Cuando el paciente es diagnosticado como positivo ante el coronavirus y esta información se hace del dominio público o se actúa bajo sospecha, el calvario que sufre el paciente y su entorno familiar se vuelve muy complejo. Varias son las reacciones de rechazo que muestra la sociedad en contra del infectado y su familia.

En primera instancia hay gente que niega, de manera contundente, la existencia del virus; sin embargo, la actitud cambia en forma radical cuando alguien conocido o cercano se entera, por otros medios, de la existencia de algún contagiado en la aldea; en estos casos es usual la reacción en forma violenta. Entonces, la actitud de rechazo hacia el contagiado, la familia y los cuidadores se vuelve un drama tan o más cruel que la enfermedad misma. En un pueblo de la etnia zoque se supo, por rumores, de la existencia de una paciente que dio positivo a coronavirus; a través de las redes sociales se difundió la invitación para quemar la casa de quien se sospechaba infectada. Ahora sí el virus existía y había que terminar 
de raíz el problema incendiando la vivienda junto con sus habitantes. Por fortuna no se llevó a cabo el incendio, puesto que la paciente abandonó el poblado con celeridad.

Ser diagnosticado como positivo portador de coronavirus es todo un estigma que se extiende a los trabajadores en el área de salud por asociarse como portadores del virus, esto al estar en contacto directo con este tipo de pacientes, incluso cuando no atiendan casos de COVID-19. De esta manera el paciente, su familia, la enfermedad y el personal de salud se convierten en una amenaza, implicando rechazo social, prácticamente generalizado, por el temor infundado y exacerbado de contagio. Este rechazo social puede desatar diferentes comportamientos que van desde la agresión física, verbal, actos profundamente discriminatorios como prohibirles el uso de transporte colectivo, el ingreso a tiendas e incluso se les han negado el acceso al domicilio de algunos de sus vecinos. Así, los pacientes y su entorno se convierten de un momento a otro - producto generalmente de la ignorancia- en enemigos sociales que constituyen una amenaza a la salud; esto sin importar que las personas aparentemente sanas no vigilen las medidas sanitarias que tanto se difunden por diversos medios. Otro tanto sucede con pacientes muertos por COVID, los cuales son rechazados por parte de la «comunidad» para no ser enterrados en el panteón de la aldea; el entierro en muchos casos se hace en forma clandestina, de noche y en solitario, sin mayores protocolos mortuorios.

El rumor de que alguna persona esté enferma o de que en algún pueblo haya casos positivos de coronavirus ha convertido, casi automáticamente, a las localidades en pueblos de rechazo, procurando evitar el acercamiento a ellos por el temor al contagio. En el estado de Chiapas se registró un caso en el que un indígena contagiado de la etnia zoque optó por el suicidio justamente por toda esta presión social, entre otros factores (Mariscal, 2020; Mariscal, 2021; Méndez y Observatorio de las Democracias, 2020).

De igual forma, en este contexto el hecho de ser extranjero, y muy particularmente de origen europeo, se convirtió en un estigma. Con frecuencia se les calificó como potenciales portadores del coronavirus. Finalmente, de manera general, los ritos funerarios de personas muertas a causa de COVID-19 han tenido un protocolo especial: se hacen con la menor pompa. A pesar de las evidencias concretas de la letalidad del padecimiento, ha sido común observar que se mantienen las viejas prácticas y no siempre se han seguido las indicaciones de higiene, como el distanciamiento social para disminuir los riesgos de contagio de la pandemia. 


\section{La saliva como auxiliar terapéutico de «ojo»}

El uso de la saliva humana como auxiliar terapéutico en la etnomedicina es bastante común (Zolla et al., 1988). Es una práctica que señala un contraste con la medicina alópata, muy en especial con la COVID-19, pues se advierte que la propagación del coronavirus es justamente por medio de la saliva. En este apartado, la idea es colocar «cara a cara» dos sistemas conceptuales del uso de la saliva: uno, que la percibe como auxiliar terapéutico en tratamientos específicos de «ojeadura»; otro, que la considera un vehículo transmisor del coronavirus, además de ser potencialmente dañina.

La persona que provoca «ojo» u «ojeadura» puede, o no, saber que posee la mirada «caliente» o conocer su condición por la experiencia al provocar accidentalmente - la sobrecarga de calor. Esto puede verse cuando le piden curar el mal que ha provocado, por ejemplo, a un niño, untando con la saliva una cruz en varias partes del cuerpo (articulaciones, frente, espalda y la planta de los pies). Sin embargo, es del dominio popular que hay personas que poseen «ojo caliente» (en especial los borrachos, embarazadas, menstruantes y gemelos) y que constituyen una seria amenaza por provocar «ojeadura», ya sea intencional o accidental.

La inyección de sobrecarga de calor — producto de la admiración por la belleza que provoca la persona, animal, planta o tarea realizada - se introduce en el cuerpo a través de los ojos, desequilibrando el balance térmico. En un bebé o niño esto provoca reacciones, como llanto continuo, incomodidad general, pérdida de apetito, cuadros diarreicos, temperatura, deshidratación, entre otras manifestaciones clínicas que, de no atenderse según los cánones tradicionales, pueden provocar la muerte. Al respecto, existen fórmulas para protegerse ante la amenaza de ser víctima de «ojo». Una de ellas consiste en portar talismanes como semillas de ojo de venado, listones de color rojo y pulseras de ámbar. Por su parte, personas que sospechen tener el «ojo caliente» deberán pedir permiso a los padres del bebé para poner con su saliva una cruz en la frente, o bien, abrazarlos o besarlos para quitarse, digamos, el antojo de tener entre sus brazos a jsemejante belleza! Sin embargo, ahora, con la amenaza del coronavirus, en especial las personas sospechosas o portadoras del virus deberán actuar con mucha cautela para no ser fuente de contagio al pretender usar la saliva humana como elemento terapéutico. Recordemos que el contagio de coronavirus, desde la visión de la medicina alópata, se hace justamente a través de la saliva humana. 


\section{Consideraciones finales}

En este trabajo se contrastan dos visiones de la medicina con respecto a las formas de percibir la enfermedad, en especial de la COVID-19. Por un lado, la medicina alópata identifica al humano como potencial portador y difusor del virus por medio de la saliva; por otro, la etnomedicina, aunque reconoce al coronavirus como el causante de la pandemia, no concibe al humano como agente transmisor directo del virus, sino que el contagio se da desde el «aire contaminado» hasta el humano. En todo caso, se cree que «el aire frío, sucio, contaminado» es capaz de transportarse a través de grandes distancias e infectar a personas que encuentra a su paso cuando estas lo respiran o aspiran. Se cree que el contagio de la COVID-19 no se adquiere a través del ojo, toda vez que la mirada inyecta calor y no frío, como es clasificada térmicamente la pandemia COVID-19. La inyección de calor a través de la mirada provoca en la víctima cuadros febriles como respuesta a acciones de envidia u «ojeadura».

Como se ha advertido, en la concepción de la medicina zoque el origen causal de los padecimientos, siempre y cuando sean de origen natural o sobrenatural, se concibe como amenaza externa en la que el humano es la víctima y no el agente transmisor de infecciones. En muchas comunidades indígenas, si se llega a conocer o sospechar que una persona es capaz de transmitir/enviar una enfermedad en forma directa o indirecta, se podría desatar una ola de venganzas. Así, por ejemplo, la práctica de envenenamiento intencional da pie al desarrollo de serios conflictos sociales.

Contraria a la terapéutica alópata, en la medicina indígena la saliva humana es un auxiliar muy socorrido en el tratamiento de enfermedades clasificadas con un origen sobrenatural y de propiedad «caliente», en especial en el tratamiento de

«ojo u ojeadura» en el que se unta saliva al paciente en varias partes del cuerpo formando una cruz. En la medicina alópata, en cambio, el coronavirus se transmite por medio de la saliva. En conclusión, son visiones encontradas. En este sentido, la información epidemiológica brindada a la población en general debe ser lo más sencilla posible, con la finalidad de que sea comprensible. Un área de oportunidad al respecto es traducirla a todas las lenguas originarias con el objetivo de modificar las costumbres y prácticas relacionadas con la emergencia sanitaria y así contribuir a superarla.

Ahora bien, por un lado, mucha gente niega abiertamente la existencia real del coronavirus argumentando, entre otras cuestiones, que se trata de un invento del gobierno para controlar a la gente manteniéndola confinada en casa. 
Por otro lado, la actitud respecto a la creencia del coronavirus cambia de forma radical cuando se rumora que algún vecino de la aldea, conocido o no, ha sido contagiado; es entonces cuando, con frecuencia, se desata una ola de ataques

y violencia en contra del paciente, la familia, cuidadores y el personal de salud, incitando, incluso, a quemar la casa del enfermo. Otros más tienen una actitud egoísta ante la enfermedad al declarar: «de algo tenemos que morir», actitud que coloca en riesgo al resto de la población que, quizá, sigue las reglas de higiene y cuidados.

Finalmente, es preciso mencionar que los pueblos indígenas no cuentan con servicios médicos hospitalarios para la atención de COVID-19. En caso de contagio, los pacientes son canalizados a las ciudades cercanas donde existen mayores probabilidades de ser atendidos. Los únicos municipios en el estado de Chiapas que, durante el periodo de estudio de este artículo, fueron clasificados con semáforo verde al estar libres de contagio, como islas, rodeados de municipios que tampoco presentaron casos, fueron cinco; cuatro de estos en territorio indígena zoque y uno tsotsil, todos en el noroeste del estado de Chiapas. Fueron comunidades serranas y son poblaciones dispersas. Chiapas pasó del semáforo COVID rojo a naranja el 20 de julio de 2020 (Secretaría de Salud Chiapas Oficial, 2020); el 31 de agosto pasó a amarillo (Milenio, 2020c) y el 20 de noviembre de 2020 se declaró en semáforo epidemiológico verde (Valle, 2020), situación que indicó volver a la llamada «nueva normalidad».

\section{Bibliografía citada}

Camacho, Zósimo. (2020). Pandemia: 16 millones de indígenas en vulnerabilidad absoluta. Contralínea, disponible en: <https://contralinea.com.mx/pandemia-16-millones-de-indigenas-en-vulnerabilidad-absoluta/> (consulta: 04/06/2021).

Diario Oficial de la Federación (DOF). (2020). Acuerdo por el que se establecen acciones extraordinarias para atender la emergencia sanitaria generada por el virus SARS-CoV2. Diario Oficial de la Federación, disponible en: <https://www.dof.gob. $\mathrm{mx} /$ nota_detalle.php?codigo $=5590914 \&$ fecha $=31 / 03 / 2020 \&$ print $=$ true $>$ (consulta: 05/05/2020).

El informador. (2020). Confirman primer caso de coronavirus en Chiapas. El Informador. 1 de marzo, disponible en: <https://www.informador.mx/mexico/Confirman-primercaso-de-coronavirus-en-Chiapas-20200301-0050.html> (consulta: 28/04/2020).

Guiteras, Calixta. (1988). Los peligros del alma. Visión del mundo de un tzotzil. La Habana, Cuba: Editorial de Ciencias Sociales.

Imberton, Gracia. (2002). La vergüenza: enfermedad y conflicto en una comunidad chol. México: Programa de Investigaciones Multidisciplinarias sobre Mesoamérica y el Sureste-Instituto de Investigaciones Antropológicas-Universidad Nacional Autónoma de México (PROIMMSE-IIA-UNAM). 
Infobae. (2020a). Semáforo del coronavirus 14 de mayo. Los 10 estados en verde con nivel de alerta baja. Infobae, disponible en: <https://www.infobae.com/america/ mexico/2020/05/14/semaforo-del-coronavirus-14-de-mayo-los-10-estados-en-verde-con-nivel-de-alerta-baja/> (consulta: 19/05/2020).

Infobae. (2020b). Coronavirus en México: estas son las fechas a tomar en cuenta. Infobae, disponible en: <https://www.infobae.com/america/mexico/2020/03/30/coronavirusen-mexico-estas-son-las-fechas-a-tomar-en-cuenta/> (consulta: 28/04/2020).

Infobae. (2020c). Estos son los 324 municipios de la Esperanza que reiniciarán actividades el 18 de mayo. Infobae, disponible en: <https://www.infobae.com/america/mexico/2020/05/17/estos-son-los-324-municipios-de-la-esperanza-que-reiniciarian-actividades-el-187-de-mayo/> (consulta: 25/04/2020).

Infobae. (2020d). Semáforo del coronavirus en México: estos son los estados en rojo con nivel de alerta máxima. Infobae, disponible en: <https://www.infobae.com/america/ mexico/2020/05/13/semaforo-del-coronavirus-en-mexico-13-de-mayo-estos-sonlos-estados-en-rojo-con-nivel-de-alerta-maxima/> (consulta: 20/03/2020).

Infobae. (2020e). Coronavirus en México: suman 1,221 muertos y 12,872 casos confirmados. Infobae, disponible en: <https://www.infobae.com/america/mexico/2020/04/25/ coronavirus-en-mexico-son-1221-muertes-y-12872-casos-confirmados/> (consulta: 28/03/2020).

Instituto Nacional de Estadística y Geografía ( INEGI). (2000). XIl Censo General de Población y Vivienda. México: Instituto Nacional de Estadística y Geografía.

Ledesma, Fermín. (2020). Indígenas y epidemias en Chiapas. Un recuento desde las monatañas zoques, Ojarasca, La Jornada, 20 de abril, disponible en: <https://ojarasca. jornada.com.mx/2020/04/10/indigenas-y-epidemias-en-chiapas-un-recuento-desde-las-montanas-zoques-6298.html\#: :text=UN\%20RECUENTO\%20DESDE\%20 LAS\%20MONTA\%C3\%91AS\%20ZOQUES,FERM\%C3\%8DN\%20LEDESMA\%20 DOM\%C3\%8DNGUEZ\&text=En\%20el\%20caso\%20de\%20los,una\%20pronta\%20colonizaci\%C3\%B3n\%20y\%20subordinaci\%C3\%B3n> (consulta: 10/02/2021).

López-Austin, Alfredo. (1980). Cuerpo humano e ideología. México: UNAM.

López, Isaí. (2020). Reportan 24 nuevos casos positivos de CovID-19 en Chiapas: con lo que suman 290 contagios. Diario del Sur, disponible en: <https://www.diariodelsur. com.mx/local/reportan-24-nuevos-casos-positivos-de-covid-19-en-chiapas-con-loque-suman-290-contagios-5200163.html> (consulta: 03/02/2020).

Mariscal, Ángeles. (2020). Se suicida en Chiapas paciente con COVID-19, un indígena zoque de Ocosingo. Chiapas paralelo, disponible en: <https://www.chiapasparalelo.com/ noticias/chiapas/2020/04/se-suicida-en-chiapas-paciente-con-covid-19-un-indigena-zoque-de-ocosingo/> (consulta: 15/04/2020).

Mariscal, Ángeles. (2021). Miedo y desinformación, factores en el suicidio de indígena contagiado con CovID-19. Chiapas paralelo, disponible en: <https://www.filac.org/ wp/comunicacion/actualidad-indigena/miedo-y-desinformacion-factores-en-el-suicidio-de-indigena-contagiado-con-covid-19/> (consulta: 10/02/2021).

Milenio. (2020a). Coronavirus en México, 27 de abril: noticias de hoy sobre el covid-19, Milenio, disponible en: <https://www.milenio.com/politica/coronavirus-mexico-27-abril-noticias-covid-19> (consulta: 28/04/2020). 
Milenio. (2020b). Casos de coronavirus en México por estado. Milenio, disponible en: <https://www.milenio.com/estados/coronavirus-casos-mexico-mapa-26-mayo> (consulta: 01/06/2020).

Milenio. (2020c). Colima, el único estado en semáforo rojo; hay 10 entidades en amariIlo, Milenio, disponible en: <https://www.milenio.com/ciencia-y-salud/semaforo-covid-mexico-situacion-actual-31-agosto-13-septiembre> (consulta: 04/09/2020).

Méndez Gómez, Delmar/ Observatorio de las Democracias (ODEMCA). (2020). Protegernos la vida: acciones frente al COVID-19 en los pueblos indígenas del sur de México. Chiapas paralelo, disponible en: <https://www.chiapasparalelo.com/ opinion/2020/04/protegernos-la-vida-acciones-frente-al-covid-19-en-los-pueblosindigenas-del-sur-de-mexico/> (consulta: 19/05/2020).

Náfate, Elam. (2020). Chiapas en color verde y casi listo para regresar a la Nueva Normalidad. El Heraldo de Chiapas, 13 de mayo, disponible en: <https://www. elheraldodechiapas.com.mx/local/autoridades-declaran-en-chiapas-75-municipios-en-condiciones-para-la-nueva-normalidad-pandemia-covid19-coronavirus-5223833.html> (consulta: 19/05/2020).

Organización Mundial de la Salud (OMS). (2020). Una guía de las orientaciones de la OMS. Organización Mundial de la Salud, disponible en: <https://www.who.int/es/news$\mathrm{room} /$ feature-stories/detail/a-guide-to-who-s-guidance> (consulta: 10/02/2021).

Page, Jaime. (2011). El mandato de los dioses. Etnomedicina entre los tzotziles de Chamula y Chenalho, Chiapas. México: PROIMMSE-IIA-UNAM.

Pitarch, Pedro. (2000) «Almas y cuerpo en una tradición indígena tzeltal», Archives de sciences sociales des religions [en línea], 112, octubre-diciembre, disponible en: $<$ http://journals.openedition.org/assr/20245> doi: 10.4000/assr.20245, (consulta: 09/09/2020).

Reyes, Laureano. (1988). Introducción a la medicina zoque, una aproximación etnolingüística. En Laureano Reyes y Susana Villasana (eds.) Estudios Recientes en el Área Zoque (pp. 158-383). México: Universidad Autónoma de Chiapas.

Secretaría de Salud Chiapas Oficial (2020). En semáforo naranja, Chiapas debe mantener las medidas sanitarias preventivas de COVID-19. [Publicación de estado]. Facebook, disponible en: <https://www.facebook.com/SaludChiapasOficial/ posts/2746028052347381/>

Valle, Montserrat. (2020). Otro estado pasa a verde en el semáforo de coviD EN México: Chiapas se une a Campeche, pero seis podrían regresar a rojo. Xataka México, 20 de noviembre, disponible en: <https://www.xataka.com.mx/medicina-y-salud/otroestado-pasa-a-verde-semaforo-covid-mexico-chiapas-se-une-a-campeche-seis-podrian-regresar-a-rojo> (consulta: 09/02/2021).

Villasana, Susana. (1995). Identidad étnica entre los zoques de Chiapas. Estudio comparativo. Tesis de maestría. México: Escuela Nacional de Antropología e Historia.

Villasana, Susana. (2006). Los zoques de Chiapas y los programas de gobierno. En Dolores Aramoni, Thomas Lee y Miguel Lisbona (eds.), Presencia zoque (pp. 75-95). Tuxtla Gutiérrez, Chiapas, México: Universidad de Ciencias y Artes de Chiapas. 
Zolla, Carlos, Carlos Campillo y Sofía del Bosque. (1988). Medicina Tradicional y enfermedad. México: Centro Interamericano de Estudios de Seguridad Social.

\section{Cómo citar este artículo:}

Reyes Gómez, Laureano (2021), «Percepción de la COVID-19 entre la población indígena zoque de Chiapas». Revista Pueblos y fronteras digital, 16, pp.1-23, doi: 10.22201/cimsur.18704115e.2021.v16.523. 